\title{
AVALIAÇÃO E CARCATERIZAÇÃO DE ERITROPOETINA HUMAN RECOMBINANTE
}

\author{
A.C.M. MARINHO ${ }^{1}$, C.M. CONCEIÇÃO ${ }^{2}$, F.S.Q.da SILVA $^{2}$, M. A. P. GIMENES ${ }^{3}$ \\ ${ }^{1}$ BIO-MANGUINHOS/FIOCRUZ, \\ ${ }^{2}$ INCQS/FIOCRUZ, Departamento de Química \\ ${ }^{3}$ Universidade Federal do Rio de Janeiro, Departamento de Engenharia Bioquímica \\ E-mail para contato: acarolina@ bio.fiocruz.br
}

\begin{abstract}
RESUMO - A eritropoetina humana recombinante (EPO-hr) é uma das glicoproteínas terapêuticas mais utilizadas em todo o mundo. A caracterização estrutural detalhada de glicoproteínas deve ser realizada para avaliar a reprodutibilidade lote a lote. Este estudo objetivou caracterizar e avaliar um lote (Lote A) de ingrediente farmacêutico ativo (IFA) de EPO-hr, mediante determinação de concentração de proteínas, massa molar, perfil de isoformas e pureza, utilizando absorção no UV, SDS-PAGE, 2D-PAGE e CLAE-FR, respectivamente. O sequenciamento peptídico foi determinado por espectrometria de massas com fonte de ionização do tipo electrospray e analisadores quadrupolo e TOF (EM-ESIQTOF). A concentração protéica obtida para o lote A foi de $1,1 \mathrm{mg} / \mathrm{mL}$, massa molar por SDS-PAGE de $40 \mathrm{kDa}$. O resultado obtido para 2D-PAGE evidenciaram 6 isoformas majoritárias entre pI 4,5 e 6,5. Para o ensaio de pureza, foi encontrado o percentual médio de 99\%. Pela técnica EM-ESI-QTOF foi possível identificar o sítio de O-glicosilação na serina. Pode-se, também, inferir que este sítio de O-glicosilação contém o fragmento HexNAc, pois há um incremento de massa de 203 Da entre o íon detectado com modificação e sem modificação. Sendo assim, os resultados obtidos com as diferentes metodologias visando o controle de qualidade e/ou controle em processo possibilitaram um maior entendimento das amostras de IFA de EPO-hr.
\end{abstract}

\section{INTRODUÇÃO}

A inserção da tecnologia do DNA recombinante, em 1970, com o surgimento das enzimas restrição possibilitou a manipulação genética de micro-organismos, com a clonagem dos genes de proteínas em diferentes sistemas de expressão. Pode-se pleitear então, a obtenção de produtos biológicos, principalmente de biofármacos, em quantidade considerável pelas indústrias farmacêuticas. Assim, foi possível a obtenção das moléculas de interesse em larga escala como, por exemplo, a insulina, viabilizando sua comercialização (WALSH, 2003).

Diferentes sistemas de expressão são utilizados para a produção de (bio)medicamentos, sendo cerca de $90 \%$ por E. coli, leveduras ou células de ovários de hamster chinês (Chinese Hamster Ovary cells - CHO) (DRANITSARI et al., 2011). Sistemas procariotos, como E. coli, foram os primeiros a serem manipulados para a produção de proteínas de interesse terapêutico, por serem de fácil cultivo e terem alta produtividade quando submetidos a escala industrial. Entretanto, este sistema de expressão não pode ser aplicado à produção de todas as moléculas de interesse, principalmente às proteínas mais complexas, como as proteínas glicosiladas ou glicoproteínas (proteínas que incorporam oligosscarídeos à sua cadeia polipeptídica em uma sequência consenso 
de aminoácidos), devido à ausência de aparatos bioquímicos para a realização de modificações póstraducionais como, por exemplo, formação de pontes de dissulfeto, desamidação, desaminação, gama-carboxilação e glicosilação (DRANITSARI et al., 2011 e BUTLER, 2008).

\subsection{A Eritropoetina Humana Recombinante EPO-hr}

Na produção da eritropoetina humana recombinante (EPO-hr), uma glicoproteína com 165 aminoácidos, figura 1, cujo padrão de glicosilação é análogo à proteína endógena, são empregadas células CHO. A EPO-hr possui massa molar que pode variar entre $34-40 \mathrm{kDa}$ devido à microheterogeneidade da porção oligossacarídica. Os oligossacarídeos representam $40 \%$ da massa molar da EPO-hr e podem apresentar uma estrutura bastante variada, o que deve ser avaliado, já que muitos destes oligossacarídeos são responsáveis pela interação de EPO-hr com os receptores celulares (WALSH \& JEFFERIS, 2006). Alterações na cadeia polipeptídica podem afetar sua potência (MIRE-SLUIS et al., 1996 e CASTILHO et al., 2008). Além disso, as cadeias de oligossacarídeos ligadas à cadeia polipeptídica da proteína exercem influência sobre suas propriedades farmacocinéticas (GILG et al., 1996).

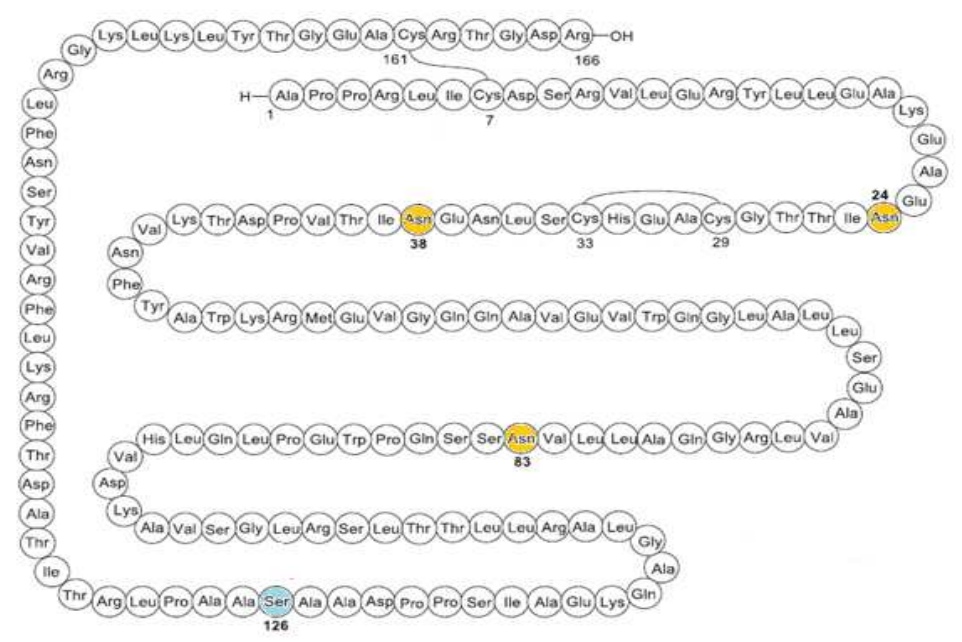

Figura 1: Sequência de aminoácidos de EPO-hr com os sítios de glicosilação identificados: N-glicosilação Asn 24; Asn 38 e Asn 83; O-glicosilação Ser 126 e as pontes dissulfeto (Adaptado de WANG et al., 2013)

O estudo da cadeia polipeptídica e dos oligossacarídeos em glicoproteínas representa um desafio analítico quando comparado a outras classes de biomoléculas e como consequência, exige um conjunto de metodologias para esta finalidade. Independentemente do padrão de glicosilação da proteína, diferentes análises podem ser empregadas para elevar o grau de precisão dos resultados, já que separadamente fornecem informações limitadas. Algumas técnicas já são utilizadas há algum tempo, como cromatografia líquida e eletroforese. Recentemente, a análise por espectrometria de massas foi incorporada a estas metodologias e vem sendo bastante utilizada e difundida para caracterizar proteínas recombinantes (JIANG et al., 2012).

Este trabalho tem o objetivo de avaliar e caracterizar um lote de Ingrediente Farmacêutico Ativo (IFA) para Eritropoetina Humana Recombinante por técnicas químicas e físico-químicas. Tais técnicas são: espectrofotometria por absorção no ultravioleta (UV), eletroforese desnaturante em gel de poliacrilamida na presença de dodecil sulfato de sódio (SDS-PAGE) e eletroforese bidimensional (2D-PAGE); cromatografia líquida de alta 
eficiência em fase reversa (CLAE-FR) e espectrometria de massas com fonte de ionização electrospray e analisadores quadrupolo-TOF (EM-ESI-QTOF).

\section{MATERIAIS E MÉTODOS}

Reagentes, padrões e amostra: Para análise de SDS-PAGE e 2D-PAGE foram utilizados reagentes do fabricante Merck exceto acrilamida (Sigma), bis-acrilamida (Sigma), Padrão de peso molecular (PPM) - Silver Stain Standards, Low Range (Bio Rad). Para análise por cromatografia em fase reversa foram utilizados reagentes Merck, e ácido trifluoracético - TFA (Tédia). Para espectrometria de massas foram utilizados os seguintes reagentes: Bicarbonato de sódio (Merck), RapiGest SF® (Waters), ditiotreitol (Merck), iodocetamida (Sigma Aldrich), tripsina (Promega), TFA (Merck), Ácido Fórmico (Merck) e acetonitrila (Merck). O lote do Ingrediente Farmacêutico Ativo de EPO-hr (purificado do sobrenadante de um cultivo) foi fornecido por uma indústria farmacêutica produtora, codificado como Lote A. Como controle foi utilizado um lote material de referência de EPO-hr, contendo $243 \mu \mathrm{g} \pm 3,6$ de alfa-EPO-hr e excipientes composto por: $60 \mathrm{mg}$ de trealose, $9 \mathrm{mg}$ de arginina, $0,3 \mathrm{mg}$ de tween $20,13,5 \mathrm{mg}$ de $\mathrm{NaCl}$ e $10,6 \mathrm{mg}$ de $\mathrm{Na}_{2} \mathrm{HPO}_{4} \cdot 1 \mathrm{H}_{2} \mathrm{O}$ com potência biológica declarada de 24393 UI.

Sistema espectrofotométrico: Foi utilizado um espectrofotômetro, modelo UV 1601Shimadzu, com cubeta de quartzo $1 \mathrm{~cm}$.

Sistema cromatográfico: Sistema Dionex Ultimate® 3000 configurado com bomba de gradiente quaternário, degaseificador, forno para coluna, injetor automático, detector DAD (Detector de Arranjo de Diodos) e software Chromeleon ${ }^{\circledR}$ versão 6.8 b Coluna analítica C18 Ace $(250 \times 4,6 \mathrm{~mm})$.

Sistema de eletroforese: Mini protean III - Bio Rad, fonte eletroforética Amershan Bioscience modelo EPS 3501 XL, densitômetro Bio Rad modelo GS-800. Foi utilizado um sistema Protean IEF Cell, strips de $7 \mathrm{~cm}$ de comprimento, faixa de $\mathrm{pH}$ de 3,0 a 10,0, kit starter para eletroforese bidimensional (Bio-rad), densitômetro, GS-800 Bio-Rad, e software PDQuest, Bio-Rad.

Concentração protéica por UV: Com o referido lote de IFA, em temperatura ambiente, foi retirada uma alíquota para uma cubeta de quartzo, procedendo a leitura da absorvância no espectrofotômetro Shimadzu utilizando como branco água obtida pelo sistema Milli-Q. Com base na leitura de Densidade Ótica (D.O.), foi calculada, a concentração de proteínas e a razão entre proteína e DNA

SDS-PAGE: Para verificar o peso molecular e a homogeneidade da amostra foi montado cassete para preparação do gel utilizando-se placas de vidro de $0,75 \mathrm{~mm}$ e gel a $12 \%$ de acrilamida. A corrida eletroforética foi desenvolvida com corrente constante de $30 \mathrm{~mA}$ e voltagem de $110 \mathrm{~V}$ com volume de aplicação de $10 \mu \mathrm{L}$ para o padrão de peso molecular e amostra. Após a finalização da corrida, o gel foi corado seguindo o protocolo estabelecido por Silva (2001) para coloração com Comassie e Blum, Bier e Gross (1987) para coloração com prata. 
2D-PAGE: Aplicou-se $125 \mu \mathrm{L}$ da amostra na cuba do sistema Protean IEF Cell. Colocou-se em seguida sobre a linha do sistema strip de $7 \mathrm{~cm}$ de comprimento, faixa de $\mathrm{pH}$ de 3,0 a 10,0 (Bio-Rad). A focalização isoelétrica ocorreu nas seguintes condições: $1^{\mathrm{a}}$ Parte: $250 \mathrm{~V}$ por $20 \mathrm{~min}$, com subida linear; $2^{\mathrm{a}}$ Parte: $4000 \mathrm{~V}$ por $2 \mathrm{~h}$, com subida linear; $3^{\mathrm{a}}$ Parte $4000 \mathrm{~V}$ até atingir um total de $20000 \mathrm{~V} / \mathrm{hora}$, com subida rápida. Terminada a primeira dimensão, os strips foram preparados para a segunda dimensão com o kit starter para eletroforese bidimensional (Bio-Rad). A segunda dimensão foi feita com o gel à concentração de $12 \%$. Após a corrida eletroforérica, o gel foi corado pelo método da prata (BLUM et al., 1987). O gel obtido foi então analisado utilizando um densitômetro, GS-800 calibrated Densitometer - Bio-Rad, e os dados foram obtidos com o auxílio do software PD-Quest BioRad. Os valores de massa molar e o ponto isoelétrico de cada spot foram determinados utilizando funções específicas do programa.

CLAE-FR: De acordo com Conceição (2003), utilizou-se coluna analítica C18 Ace, solvente A: TFA $0,1 \%$ e solvente B: TFA $0,1 \%$ em acetonitrila: 1-propanol (3:1), fluxo: $1 \mathrm{~mL} / \mathrm{min}$, gradiente: $0-5 \mathrm{~min}: 2 \% \mathrm{~B} ; 5-40 \mathrm{~min}: 80 \% \mathrm{~B} ; 40-50 \mathrm{~min}: 80 \% \mathrm{~B} ; 50-60 \mathrm{~min}$ : $2 \%$ B; 60 - 70min: $2 \%$ B, volume de injeção: $100 \mu \mathrm{L}$.

EM-ESI-QTOF: A $50 \mu \mathrm{L}$ da amostra e controle previamente dessalinizados, com concentração de $1 \mu \mathrm{g} / \mu \mathrm{L}$ foram adicionados $10 \mu \mathrm{L}$ de bicarbonato de amônio $50 \mathrm{mM}$ pH 8,5, $25 \mu \mathrm{L}$ de solução RapiGest $\mathrm{SF} \circledast 0,2 \%$ (um surfactante) e procedeu o aquecimento a $80^{\circ} \mathrm{C}$ por 15 minutos. Após 15 minutos, centrifugou-se e adicionou-se $2,5 \mu \mathrm{L}$ de ditiotreitol $100 \mathrm{mM} \mathrm{e}$ aqueceu-se novamente a $60^{\circ} \mathrm{C}$ por 30 minutos. Finalizado o tempo de aquecimento, foram adicionados $2,5 \mu \mathrm{L}$ de iodocetamida $300 \mathrm{mM}$ e as amostras e controle foram mantidas ao abrigo da luz a temperatura ambiente por 30 minutos. Após o tempo de 30 minutos foram adicionados $20 \mu \mathrm{L}$ de solução de tripsina $0,05 \mu \mathrm{g} / \mu \mathrm{L}$ e realizou-se a hidrólise enzimática a $37^{\circ} \mathrm{C}$ overnight. Adicionou-se $10 \mu \mathrm{L}$ de TFA $5 \%$ e centrifugou-se a $14000 \mathrm{rpm}$ a $6^{\circ} \mathrm{C}$ por 30 minutos. Utilizou-se para o sistema UPLC (Ultra performance liquid chromatography) coluna ACQUITY ${ }^{\mathrm{TM}}$ HSS (Waters) T3, $2.1 \times 100 \mathrm{~mm}$, fluxo $300 \mathrm{uL} / \mathrm{min}$, temperatura coluna $60^{\circ} \mathrm{C}$, solvente A: Ácido Fórmico $0,1 \%$ e solvente B: Ácido Fórmico $0,1 \%$ em acetonitrila e gradiente: 0 - 6,06: 95\% B; 6,06 - 10,06: 60\% B; 10,06 - 14,06: $15 \% \mathrm{~B} ; 14,06-16,06: 95 \% \mathrm{~B}$. E para HDMS (Waters), Modo íon positivo, capilar: $2.8 \mathrm{kV}$, cone: $30 \mathrm{~V}$, Energia de colisão baixa: Trap: 4 volts, transferência: 0 volts, Energia de colisão - elevada: Trap: 4 para 5 volts, rampa de transferência: 19 - 44 volts, scan time: 300 ms.A amostra e o controle de EPO-hr foram submetidos à análise por espectrofotometria de massas após a redução e alquilação com ditiotreitol e iodocetamida, respectivamente, e hidrólise com tripsina. Para avaliar os peptídeos encontrados experimentalmente foi utilizado o programa Biopharmalynx ${ }^{\circledR}$ para obter os peptídeos teóricos de EPO-hr a partir da hidrólise com tripsina

\section{RESULTADOS E DISCUSSÃO}

\subsection{Determinação da concentração de proteínas pela técnica de espectrofotometria por absorção no ultravioleta (UV)}

Conforme mostrado na tabela 1, pode-se concluir que o resultado para a concentração proteica foi satisfatório, já que obteve-se concentração superior a $0,3 \mathrm{mg} / \mathrm{mL}$ de acordo com a Farmacopeia Europeia $7^{a}$ edição. A relação 280/260nm apresentou valor superior a 1,5, o que evidencia que há maior conteúdo proteico que DNA. Os resultados de concentração foi igual a 
$1,0476 \mathrm{mg} / \mathrm{mL}$. A determinação da concentração de proteínas por UV é um método amplamente utilizado durante os procedimentos de purificação e separação de proteínas por ser um ensaio simples e de fácil execução. Todavia, deve-se conhecer o coeficiente de extinção molar da proteína, que para EPO-hr é igual a 1,345.

Tabela 1 - Resultado das leituras das absorvâncias dos lotes de IFA, da concentração e da relação proteína/DNA respectivamente

\begin{tabular}{ccccc}
\hline Lote IFA & $\begin{array}{c}\text { D.0. 280 } \\
\text { nm }\end{array}$ & $\begin{array}{c}\text { D.0. 260 } \\
\text { nm }\end{array}$ & $\begin{array}{c}\text { Concentração } \\
\text { mg/mL }\end{array}$ & $\begin{array}{c}\text { Relação } \\
\mathbf{2 8 0 / 2 6 0 n m}\end{array}$ \\
\hline $\mathbf{A}$ & 0,7789 & 0,4233 & 1,0476 & 1,84 \\
\hline
\end{tabular}

\subsection{Eletroforese desnaturante em gel de poliacrilamida (SDS-PAGE)}

Conforme mostra a Figura 1, o gel de SDS-PAGE para o lote A, foi possível estimar a massa molar em 40,09 $\mathrm{kDa} \pm 0,78(39,24 ; 40,77 ; 40,25 \mathrm{kDa}$ respectivamente) mediante a presença de uma única banda de EPO-hr de forma difusa. Esse formato difuso deve-se a micro heterogeneidade da porção oligossacarídeo da EPO. A micro heterogeneidade desse produto está ligada ao número de repetições das unidades lactosamina (NAcGlc-Gal), e a presença de ácido siálico no final de cada ramificação das cadeias de oligossacarídeos.

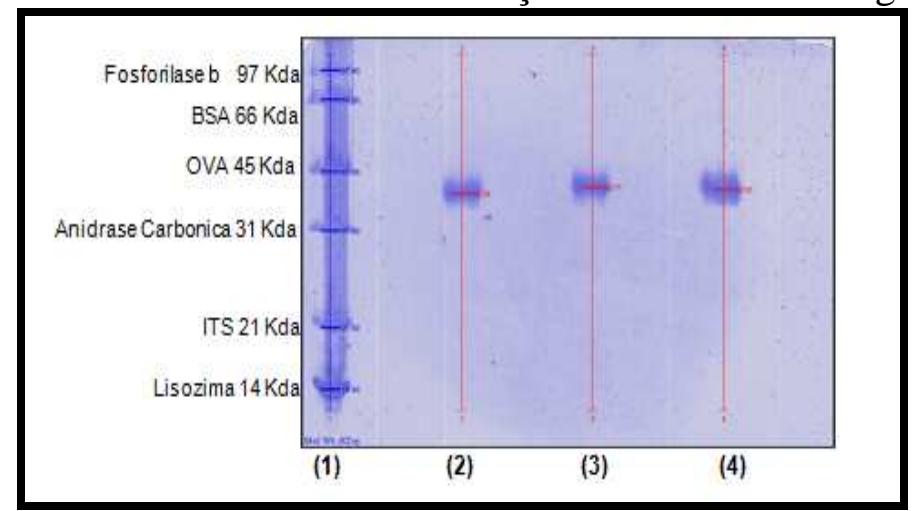

Figura 1 - SDS-PAGE para amostra de IFA lote: A. $1^{\text {a }}$ raia: Padrão de baixa massa molar; $2^{\mathrm{a}}$ a $4^{\mathrm{a}}$ raias: amostra em triplicata. Eletroforese desnaturante em gel de poliacrilamida $12 \%$ desenvolvida em sistema vertical MiniProtean III, Bio-Rad, espaçador de gel: $0,75 \mathrm{~cm}$. Corrida eletroforética realizada com corrente constante de $25 \mathrm{~mA}$ e voltagem de 110 - 150V. Tempo: 40 minutos. Volume aplicação das amostras e padrão: 10 $\mu \mathrm{L}$.

O resultado de massa molar de EPO-hr para o referido lote é coerente com os dados disponíveis na literatura que pode variar de 34-40 kDa devido à variedade da composição glicídica. Sendo assim, a estimativa é satisfatória.

\subsection{Eletroforese bidimensional (2D-PAGE)}

No gel bidimensional, conforme mostrado na Figura 2, pode-se observar uma única região (1) próxima a massa molar de $39 \mathrm{kDa}$ apresentando seis bandas majoritárias e diferentes pontos isoelétricos, variando de 4,5 a 6.5. Pode-se inferir que a produção deste lote foi eficiente, já que não foi evidenciada a presença de bandas eletroforéticas em outra região do gel bidimensional. 


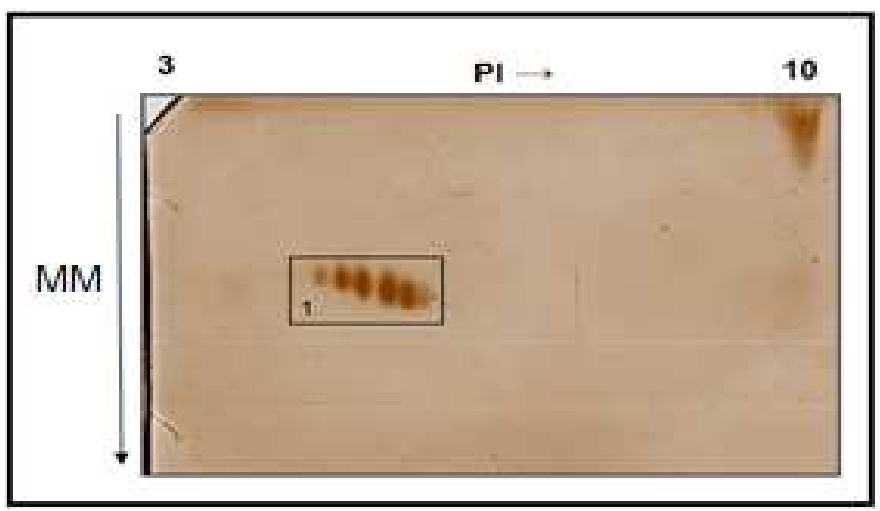

Figura 2 - Eletroforese bidimensional para EPO lote: B. Volume aplicado: $125 \mu \mathrm{L}$ de amostra e strip de $7 \mathrm{~cm}$. Primeira dimensão: Mini-Protean II Cell; Strip 3 - 10; Segunda dimensão o Mini-Protean III com gel de SDSPAGE a $12 \%$. Corrida eletroforética realizada com corrente constante de $25 \mathrm{~mA}$ e voltagem de $110-150 \mathrm{~V}$.

Tempo total: 240 minutos.

\subsection{Pureza por cromatografia líquida de alta eficiência em fase reversa (CLAE-FR)}

Conforme mostrado na Figura 3 é possível observar o perfil cromatográfico para a amostra (em preto), branco (em azul) e controle (em roxo), com resolução satisfatória. O tempo de retenção encontrado para as injeções em triplicata foram 32,815, 37,792 e 32,710 minutos e os percentuais de pureza foram $98,27,99,26$ e $98,15 \%$ respectivamente.

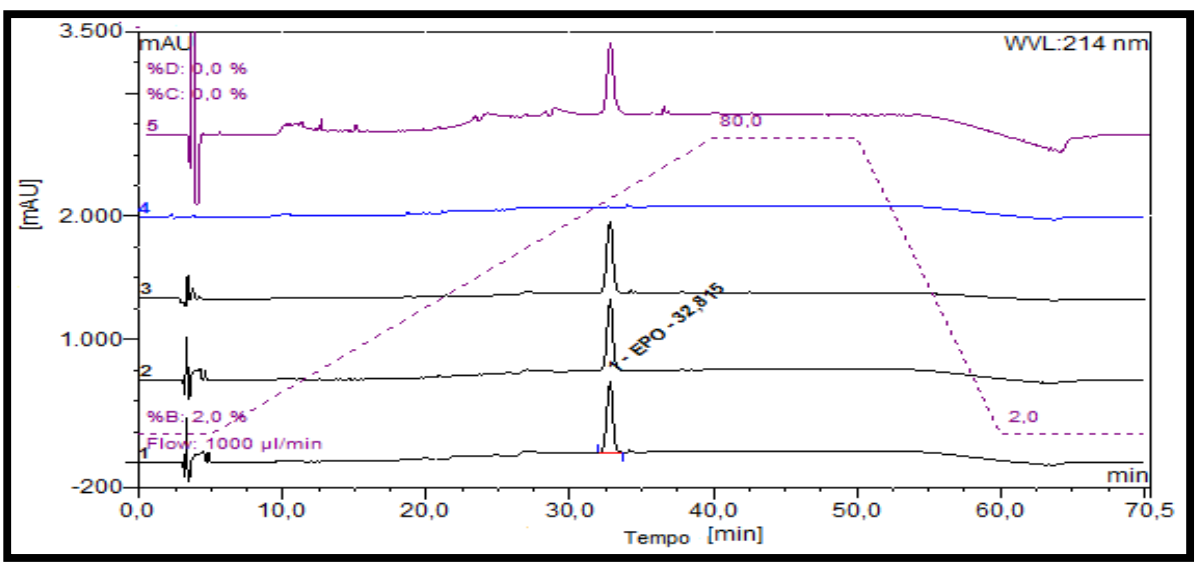

Figura 3 - Perfil cromatográfico em fase reversa. Em roxo: Controle, em rosa: Fase móvel A (branco), em preto: Amostra de IFA de EPO-hr em triplicata, linha tracejada: gradiente. Condições: Volume de Injeção: 100 $\mu$ L, Fase móvel A: 0,1\% TFA; Fase móvel B: 0,1\% TFA em ACN: 1-propanol (3:1); Coluna: C18 Ace; Fluxo: 1,0 mL/min; Comprimento de onda: $214 \mathrm{~nm}$.

\subsection{Espectrometria de massas por electrospray para EPO-hr}

$\mathrm{Na}$ Figura 4, pode ser observado o espectro de massas total (íons precursores) para a amostra. NA região de baixa massa é possível observar a distribuição referente a contaminação com polietilenoglicol (PEG), devido à diferença de relação massa/carga correspondente a $44\left(\mathrm{C}_{2 \mathrm{n}+2} \mathrm{H}_{4 \mathrm{n}+6} \mathrm{O}_{\mathrm{n}+2}\right)$ entre os sinais, referente ao material uitlizado no preparo da amostra. 


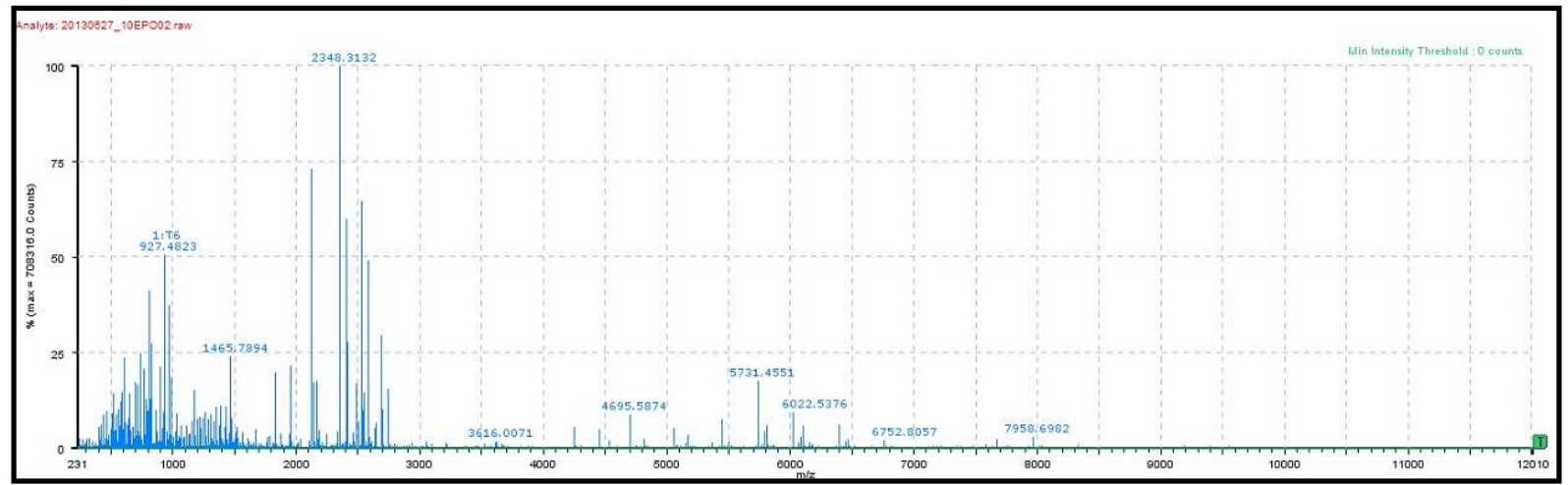

Figura 4 - Espectro total de massas referente ao lote IFA de EPO-hr. Equipamento: Espectrômetro de massas Waters Synapt G2 HDMS - tipo: ESI- QTOF

Os peptídeos ou aminoácidos APPR, R, AVSGLR, K, GK, LK e TGDR, não foram identificados os íons precursores na amostra com base no espectro total. A não identificação destes fragmentos deve-se ao seu tamanho, relativamente pequeno para sua detecção. Os fragmentos VLER, YLLEAK, EAENITTGCAEHCSLNENITVPDTK e GQALLVNSSQPWEPLQLHVDK não puderam ser confirmados, com base no espectro de fragmentos, já que somente o íon precursor foi correlacionado aos sinais encontrados no espectro total de massas conforme visto no lote $\mathrm{A}$.

Na Figura 5, pode ser observado o espectro de fragmentos relacionados ao peptídeo EAISPPDAASAAPLR, onde as séries " $y$ " e "a" identificadas para o para o controle (superior) e amostra (inferior) foram demonstradas com suas respectivas massas protonadas.

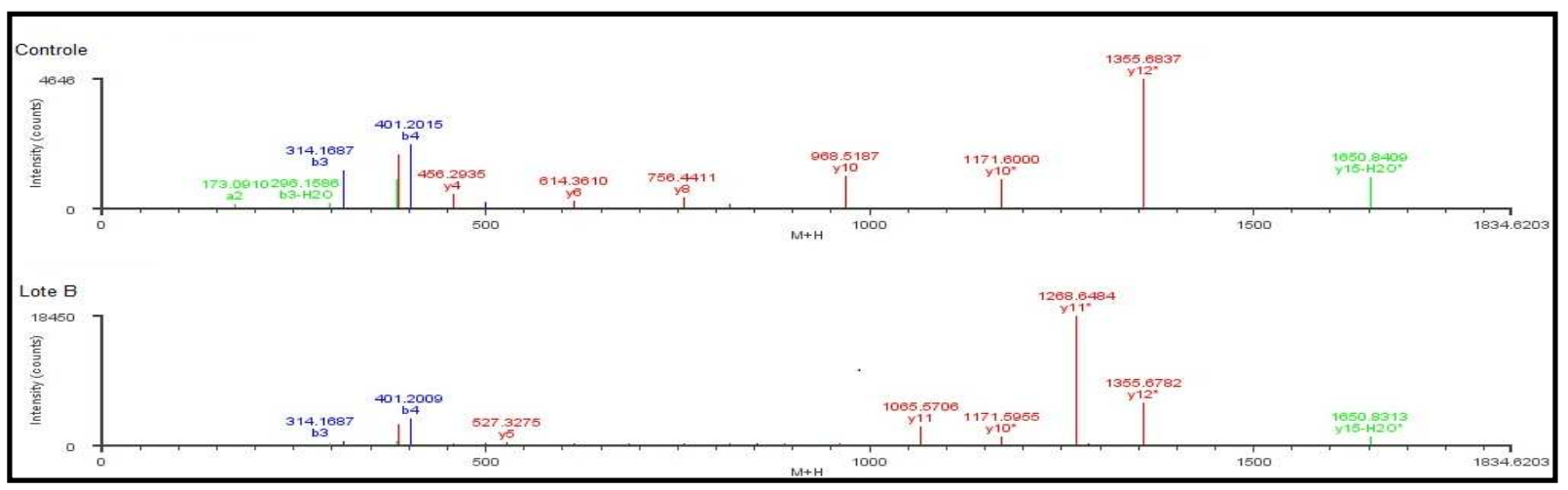

Figura 5 - Espectro de fragmentos $\mathrm{MS}^{\mathrm{E}}$ para o controle (superior) e amostra (inferior) de IFA de EPO-hr, peptídeo: EAISPPDAASAAPLR. Espectrômetro de massas Waters Synapt G2 HDMS - tipo: ESI- QTOF

As séries y12, y11, y8, y7, y6, y5 e y4, para o peptídeo EAISPPDAASAAPLR, foram identificadas tanto para o controle e amostra. Somente a séries y14 foi encontrada na amostra. Algumas séries não são visualizadas na amostra devido a intensidade do y11* (com detecção de modificação). A diferença de massa entre o íon y12 e o íon y11 é de 87,0298 Da, sugere que o sítio O-glicosilação esta posicionado no resíduo de serina na posição 6 e não na posição 12. Pode-se, ainda, inferir que este sítio de O-glicosilação contém o fragmento HexNAc (Nacetilgalactosamina), pois há um incremento de massa de $203 \mathrm{Da}$ entre o íon y11* (m/z 1268,6484) e íon do y11 (m/z 1065,5708) mostrado na Figura 5.

\section{CONCLUSÕES}


As técnicas adotas neste trabalho (SDS-PAGE, CLAE-FR, 2D-PAGE, UV e EM) contribuíram significativamente para melhor avaliação e caracterização do lote de IFA de EPO-hr. Neste trabalho foi possível estimar mediante a técnica de SDS-PAGE a massa molar de IFA de EPO-hr, sem grande variabilidade, em 40,09 $\mathrm{kDa}$ para a amostra, percentual de pureza superior a 99\% por CLAE-FR, 6 isoformas majoritárias por 2D-PAGE, $1,1 \mathrm{mg} / \mathrm{mL}$ de conteúdo protéico e 10 peptídeos dos 21 téoricos calculados pelo Biopharmalynx ${ }^{\circledR}$ foram confirmados por EM.

\section{REFERÊNCIAS}

BUTLER, M. Modificações pós-traducão em proteínas recombinantes. In: MORAES, A. M., AUguSto, E. F. P., CASTILHO, L. R.; Tecnologia De Cultivo De Células Animais: de Biofármacos a Terapia Gênica, Rio de Janeiro; Ed. Roca; p. 122-135, 2008.

CASTILHO, L. R.; Tecnologia De Cultivo De Células Animais: de Biofármacos a Terapia Gênica, Rio de Janeiro; Ed. Roca; p. 60-63, 2008.

CONCEIÇÃO, C. M. Isolamento e Caracterização Físico - Química e Química Parcial de Eritropoetina Humana Recombinante de Formulações Terapêuticas, 2003. 175 f. [Dissertação] (Mestrado em Bioquímica) Instituto de Química, Universidade Federal do Rio de Janeiro, 2003.

DRANITSARI, G.; AMIR, E.; DORWARD, K. Biosimilars of Biological Drug Therapies Regulatory, Clinical and Commercial Considerations. Drugs, V. 71 (12), p. 1527-1536, 2011.

GILG, D., RIEDL, B., ZIER, A., ZIMMERMANN, M. F., Analytical methods for the characterization and quality control of pharmaceutical peptides and proteins, using erythropoietin as an example. Pharmaceutics Acta Helvetiae; v.71; p. 383-394; 1996.

JIANG, X. G.; APOSTOL, I.; LUO, Q.; LEWIS, J.; KEENER III, R.; LUO, S.; JERUMS, M.; ZHANG, X.; WYPYCH, J., HUANG, G. Quantification of protein posttranslational modifications using stable isotope and mass spectrometry I: Principles and applications Analytical Biochemistry, V. 421, p. 506-516, 2012.

MIRE-SLUIS, A. R.; GERRARD, T.; DAS, R. G.; PADILLA, A.; THORPE, R.; Biological Assays: Their Role in the Development and Quality Control of Recombinant Biological Medicinal Products. Biologicals, v.24, p.351-362, 1996.

WALSH, G; JEFFERIS, R.; Post-translational modifications in the context of therapeutic protein. Nature biotechnology, v.24, p. 1241-1252, 2006.

WALSH, G. Biopharmaceuticals, Biochemistry and Biotechnology. 2ed. England. Wiley, p. $551,2003$.

WANG, P.; DONG, S.; SHIEH, J. PEGUERO, E.; HENDRICKSON, R.; MOORE, M.A.S.; DANISHEFSKY, S.J. Erythropoietin Derived by Chemical Synthesis. Science, V. 342, n. 6164, p. 1357-1360, dez. 2013. 